\title{
$\beta 1$-Adrenoceptor or $\alpha 1$-adrenoceptor activation initiates early odor preference learning in rat pups: Support for the mitral cell/cAMP model of odor preference learning
}

\author{
Carolyn W. Harley, ${ }^{1}$ Andrea Darby-King, ${ }^{2}$ Jennifer McCann, ${ }^{1}$ and John H. McLean ${ }^{2,3}$ \\ ${ }^{1}$ Department of Psychology and ${ }^{2}$ Division of Basic Medical Sciences, Memorial University of Newfoundland, \\ St. John's, NL, A1B 3V6, Canada
}

\begin{abstract}
We proposed that mitral cell $\beta 1$-adrenoceptor activation mediates rat pup odor preference learning. Here we evaluate $\beta 1-, \beta 2-, \alpha 1-$, and $\alpha 2$-adrenoceptor agonists in such learning. The $\beta 1$-adrenoceptor agonist, dobutamine, and the $\alpha 1$-adrenoceptor agonist, phenylephrine, induced learning, and both exhibited an inverted U-curve dose-response relationship to odor preference learning. Phenylephrine-induced learning occurred in the presence of propranolol to prevent indirect activation of $\beta$-adrenoceptors. $\alpha$ l-Adrenoceptor mediation may represent a novel mechanism inducing learning or may increase cAMP in mitral cells via indirect activation of $G A B A_{B}$ receptors. Neither the $\beta 2$-adrenoceptor agonist, salbutamol, nor the $\alpha 2$-adrenoceptor agonist, clonidine, induced learning.
\end{abstract}

Since initial ground breaking studies in Aplysia (for a review, see Pittenger and Kandel 2003) and later Drosophila (Yin and Tully 1996), there has been interest in the hypothesis that the cyclic adenosine monophosphate/protein kinase A/cyclic adenosine monophosphate response element binding protein (cAMP/PKA/ CREB) cascade might be a universal mechanism underlying learning and memory. In mammalian models there is also supporting evidence for such an assertion, but in adult rat models the associative pathways involved in recruiting cAMP activation in learning are difficult to identify (Alberini 1999). The rat pup odor preference learning model offers an advantage in that respect as the role of $\beta$-adrenoceptor activation as an unconditioned stimulus is well established (Sullivan et al. 1989, 1991a; Sullivan and Wilson 1991; Langdon et al. 1997), and more recently, a causal role for cAMP in this form of associative learning has been demonstrated (McLean and Harley 2004).

In 2003, we proposed that early odor preference learning in the week-old rat pup induced by pairing a novel odor with tactile stimulation (stroking), or with injection of the nonselective $\beta$-agonist isoproterenol, was mediated by the activation of $\beta 1$ adrenoceptors on mitral cells that interacted with glutamatergic odor input to the same cells (Yuan et al. 2003b). This interaction was proposed to produce alterations in mitral cell connectivity that altered the pup's memory of, and preference for, the novel odor. We showed that $\beta 1$-adrenoceptors are predominantly localized on mitral cells and that they are colocalized there with 5- $\mathrm{HT}_{2 \mathrm{~A}}$ receptors (Yuan et al. 2003b), which facilitate learning by potentiating the cAMP response initiated by $\beta 1$-adrenoceptors. We have also found that cAMP has a causal role in odor preference learning consistent with our hypothesis (Yuan et al. 2003a,b).

All previous work with odor preference learning and $\beta$-adrenoceptor activation has used the nonselective $\beta$-adrenoceptor agonist isoproterenol. It has not been demonstrated that selective $\beta 1$-adrenoceptor activation produces learning. Isoproter-

\footnotetext{
${ }^{3}$ Corresponding author.

E-mail mclean@mun.ca; fax (709) 777-7010.

Article and publication are at http://www.learnmem.org/cgi/doi/10.1101/ Im.62006.
}

enol, infused directly into the olfactory bulb (Sullivan et al. 2000) or given systemically (Sullivan et al. 1991a; Langdon et al. 1997), induces odor preference learning when paired with a novel odor. The nonspecific $\beta$-antagonist propranolol, infused directly into the olfactory bulb (Sullivan et al. 1992) or given systemically (Sullivan et al. 1991a), prevents odor preference learning induced by stroking. This is consistent with the hypothesis that $\beta 1$ adrenoceptors in the olfactory bulb are the critical substrate of the unconditioned stimulus in odor preference learning. Together these results have been taken as evidence that $\beta$-adrenoceptors are necessary and sufficient for early odor preference learning (Sullivan et al. 1989, 2000).

Odor preference learning induced by the naturalistic pairing of odor and stroking is proposed to be mediated by the pairing of odor and norepinephrine release in the olfactory bulb (Sullivan et al. 1991b). Stroking produces sustained locus coeruleus activation in week-old pups (Nakamura et al. 1987), and increased norepinephrine release in the olfactory bulb during the odor and stroking paradigm has been demonstrated (Rangel and Leon 1995).

This odor plus locus coeruleus activation model of odor preference learning is confirmed by the work of Moriceau and Sullivan (2004). They proposed that the restricted period for odor preference learning was governed by the development of $\alpha 2$ adrenoceptor autoinhibition in locus coeruleus. By pharmacologically blocking $\alpha 2$-adrenoceptor inhibition and by directly activating the locus coeruleus with a combination of the $\alpha 1$ adrenoceptor agonist phenylephrine and a cholinergic agonist, they extended the critical period for odor preference learning to older pups. Direct activation of bulbar $\beta$-adrenoceptors using isoproterenol was also effective in inducing odor preference learning in the older pups that normally do not display such learning.

Our work has focused on the cellular events underlying memory formation in the olfactory bulb. We have shown that effective odor and reward pairings increase cAMP (Yuan et al. 2003b; McLean et al. 2004) and increase CREB phosphorylation (McLean et al. 1999) in olfactory bulb mitral cells. Enhancing or interfering with normal CREB levels by using a viral vector shifts the inverted $U$ dose-response curve for isoproterenol-induced 


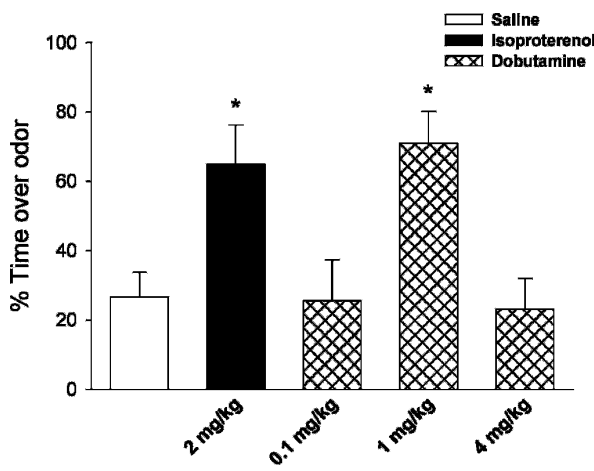

Figure 1. The $\beta 1$-adrenoceptor agonist, dobutamine, is effective as the unconditioned stimulus in effecting associative learning in one-trial training given at postnatal day 6 and tested for terpinene odor preference on postnatal day 7. Isoproterenol, a general $\beta$-adrenoceptor agonist, is used as the positive control for learning. $\mathrm{N}$ values range from eight to 10 pups for each group. ${ }^{*} P<0.05$.

odor preference learning to the left or right, respectively. This is consistent with a critical role for the PKA/CREB cascade in this form of learning. We have also shown that 5-HT facilitates the action of isoproterenol in elevating cAMP (Yuan et al. 2003a) and in producing odor preference learning (Price et al. 1998). These data led to the hypothesis that $\beta 1$-adrenoceptors on mitral cells, with support from the colocalized $5-\mathrm{HT}_{2 \mathrm{~A} / \mathrm{C}}$ receptors (Yuan et al. $2003 \mathrm{~b}$ ), interact with odor input to provide the cellular signals for learning and memory (McLean and Harley 2004).

However, the roles of specific adrenoceptor agonists have not been tested in pup odor preference learning. Norepinephrine released by locus coeruleus activation would interact with all adrenoceptor subtypes present in the olfactory bulb. Both $\beta 1$ and $\beta 2$-adrenoceptor subtypes are present in the olfactory bulb (Nicholas et al. 1993; Woo and Leon 1995) and would be activated by isoproterenol. $\alpha$-Adrenoceptor subtypes also occur in the olfactory bulb (McCune et al. 1993). The $\alpha 1$-adrenoceptor subtype enhances odor learning in adult rat (Spreng et al. 2001), while the $\alpha 2$-adrenoceptor subtype plays a role in memory in other brain regions (Sara and Devauges 1989; Arnsten and Leslie 1991; Carlson et al. 1992; Coull et al. 1996; Birnbaum et al. 2000; Gibbs and Summers 2003). Thus, to evaluate our hypothesis, we examine here the effectiveness of $\beta 1-, \beta 2-, \alpha 1-$, and $\alpha 2$ adrenoceptor agonists as unconditioned stimuli for early odor preference learning.

Sprague-Dawley rat pups of both sexes were used in this study. Litters were culled to 12 pups/litter on postnatal day (PND) 1 (the day of birth is considered PND0). The dams were maintained under a 12-h light/12-h dark cycle, with ad libitum access to food and water. All experimental procedures were approved by the Memorial University Institutional Animal Care Committee, which abides by the standards set by the Canadian Council on Animal Care. No more than one male and one female pup were used for each condition per litter.

All experiments followed the same basic design. Each adrenoceptor was tested with a separate group of litters. Pups were removed from the dam on PND6 10 min before training and placed on terpinene-scented bedding $(0.25 \mathrm{~mL} \alpha$-terpinene, $\mathrm{Al}$ drich Chemical Company/500 mL cedar chip bedding) in a manner described previously (Langdon et al. 1997). On the day following training (PND7), pups were removed individually from the dam and tested for odor preference by using a two odor choice test as described previously (Sullivan and Leon 1987; Sullivan et al. 1989; Langdon et al. 1997; Price et al. 1998; McLean et al. 1999). Briefly, each pup was placed in a neutral zone and given five 1-min tests. The amount of time over terpinene was calculated as the percentage of time the pup spent over that odor divided by the total time over either odor.

Drugs were obtained from Sigma Canada. As a positive learning control, isoproterenol ( $2 \mathrm{mg} / \mathrm{kg}$ in $50 \mu \mathrm{L}$ saline), which is known to induce learning by activating $\beta$-adrenoceptors (Sullivan et al. 1989; Sullivan and Wilson 1994; Langdon et al. 1997; Price et al. 1998), was injected subcutaneously (s.c.) 40 min before odor pairing. For a nonlearning control, saline $(50 \mu \mathrm{L})$ was injected in other pups.

The adrenoceptor agonists tested were dobutamine, a $\beta 1$ adrenoceptor agonist, at $0.1,1$, and $4 \mathrm{mg} / \mathrm{kg}$, intraperitoneally (i.p.) (five litters, 34 pups); salbutamol, a $\beta 2$-adrenoceptor agonist at $0.1,1$, and $3 \mathrm{mg} / \mathrm{kg}$, i.p. (seven litters, 68 pups); phenylephrine, an $\alpha 1$-adrenoceptor agonist at $0.5,1$, and $2 \mathrm{mg} / \mathrm{kg}$, i.p. (six litters, 32 pups); and clonidine, an $\alpha 2$-adrenoceptor agonist at 5, $10,20,50,100$, and $200 \mu \mathrm{g} / \mathrm{kg}$ s.c. (10 litters, 59 pups). All agonists were given $30 \mathrm{~min}$ prior to odor exposure, and the pup was returned to the dam until training. An additional condition was added after the initial $\alpha 1$-adrenoceptor agonist results were obtained; propranolol $(20 \mathrm{mg} / \mathrm{kg}$, i.p.) + phenylephrine (at 1 or 2 $\mathrm{mg} / \mathrm{kg}$ i.p.). Propranolol, a $\beta$-adrenoceptor antagonist was given $15 \mathrm{~min}$ prior to phenylephrine. These groups were tested against the learning effective dose of phenylephrine $(1 \mathrm{mg} / \mathrm{kg})$ as well as the usual controls (six litters, 46 pups). This added condition was required because $\alpha 1$-adrenoceptors are present in both the locus coeruleus (McCune et al. 1993) and olfactory bulb (McCune et al. 1993; Pieribone et al. 1994), while $\beta$-adrenoceptors are present in the olfactory bulb (Woo and Leon 1995) but not in the locus coeruleus (Nicholas et al. 1993). Thus, blocking the $\beta$-adrenoceptors in the olfactory bulb, while activating $\alpha 1$-adrenoceptors, would rule out $\beta$-adrenoceptor involvement in learning in the presence of $\alpha 1$-adrenoceptor activation.

Dobutamine ( $\beta 1$-adrenoceptor agonist) displayed an inverted U-curve effect (Fig. 1), being effective at a dose of $1 \mathrm{mg} / \mathrm{kg}$, and ineffective at a lower, or higher, dose $\left(\right.$ ANOVA $F_{[4,27]}=5.642$, $P<0.01)$. Post hoc analysis using the Dunnett multiple comparison test confirmed that the positive control (isoproterenol) group was significantly different from the odor-saline control $(P<0.05)$. With isoproterenol, pups showed a preference for the odor CS spending $64.9 \pm 11.3$ (SEM)\% of time over the terpinene compared with saline-odor nonlearning control at $26.7 \pm 7.1 \%$. With dobutamine $(1 \mathrm{mg} / \mathrm{kg})$, pups averaged $71.0 \pm 9.1 \%$ of the time over terpinene, and this was also significantly different $(P<0.05)$ from saline-odor control. Neither the 0.2 nor $4 \mathrm{mg} / \mathrm{kg}$ dobutamine dose produced preferences significantly different from the saline nonlearning control.

Salbutamol ( $\beta 2$-adrenoceptor agonist) did not differ signifi-

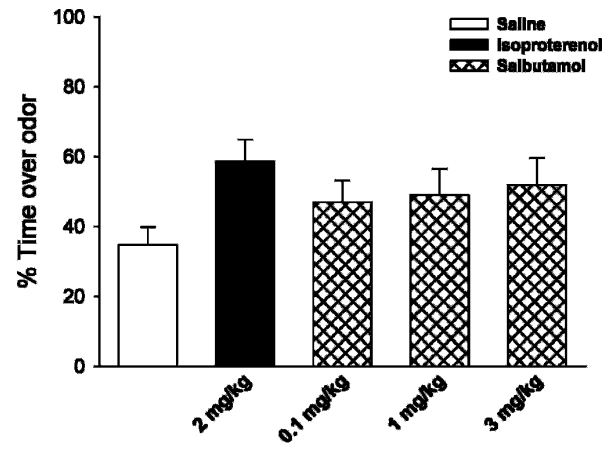

Figure 2. The $\beta 2$-adrenoceptor agonist, salbutamol, is not effective as an unconditioned stimulus for early preference learning as the time spent over the conditioned odor is not significantly different from the nonlearning (saline + terpinene odor) control. $\mathrm{N}$ values are 16 pups for each group. 
cantly from either the saline (nonlearning) control or the isoproterenol (learning) control (Fig. 2). In a planned Student $t$-test, the latter two groups differed significantly from each other (nonlearning control, $34.7 \pm 5.2 \%$; learning control $58.6 \pm 6.3 \%$; $P<0.01$ ).

Phenylephrine ( $\alpha 1$-adrenoceptor agonist) also displayed an inverted U-curve effect (Fig. 3), being effective at a dose of 1 $\mathrm{mg} / \mathrm{kg}$ and ineffective at a lower, or higher, dose (ANOVA, $\left.F_{[4,21]}=6.724, P<0.01\right)$. Post hoc analysis using the Dunnett multiple comparison test confirmed that the positive control (isoproterenol) group was significantly different from the odorsaline control $(P<0.05)$. With isoproterenol, the pups showed preference for the odor CS spending $67.0 \pm 9.0 \%$ of the time over the terpinene compared with the saline-odor nonlearning control at $33.6 \pm 4.6 \%$. With phenylephrine $(1 \mathrm{mg} / \mathrm{kg})$, pups averaged $64.2 \pm 12.1 \%$ of the time over terpinene, and this was also significantly different $(P<0.05)$ from the saline-odor control. Neither the 0.5 nor $2 \mathrm{mg} / \mathrm{kg}$ phenylephrine dose was significantly different from the saline (nonlearning) control.

In the presence of the $\beta$-adrenoceptor antagonist propranolol (Fig. 4), $1 \mathrm{mg} / \mathrm{kg}$ phenylephrine was still an effective unconditioned stimulus $\left(F_{[3,42]}=9.804, P<0.0001\right)$. In post hoc analysis using the Dunnett multiple comparison test, phenylephrine $(1 \mathrm{mg} / \mathrm{kg}$ ) with saline (odor preference of $49.8 \pm 7.4 \%)$ or with propranolol (odor preference of $58.9 \pm 5.4 \%$ ) was significantly different from saline only (odor preference of $23.9 \pm 4.1 \%$ ). Phenylephrine with propranolol was not significantly different from phenylephrine with saline in inducing a preference. The 2 $\mathrm{mg} / \mathrm{kg}$ dose of phenylephrine was still ineffective (odor preference of $26.0 \pm 4.2 \%$ ) in the presence of propranolol and did not differ from the nonlearning saline alone group.

Clonidine ( $\alpha 2$-adrenoceptor agonist) failed to produce an odor preference at any concentration (Fig. 5). The nonlearning and learning controls performed as expected, spending $25.0 \pm 4.9 \%$ and $66.3 \pm 8.2 \%$ of the time, respectively, over the odor CS. A one-way ANOVA was highly significant $\left(F_{[7,51]}=5.893, P<0.0001\right)$. However, the Dunnett multiple comparison post hoc tests showed only the isoproterenol group differed from the saline control group $(P<0.01)$.

In any study using systemic drugs, there are concerns about site of action and selectivity of action. While the present study builds on earlier evidence for intrabulbar effectiveness of a $\beta$-adrenoceptor agonist (Sullivan et al. 2000) and antagonist (Sullivan et al. 1992) and on intrabulbar 5-HT depletion (McLean et al. $1993,1996)$ to argue that the critical necessary and sufficient

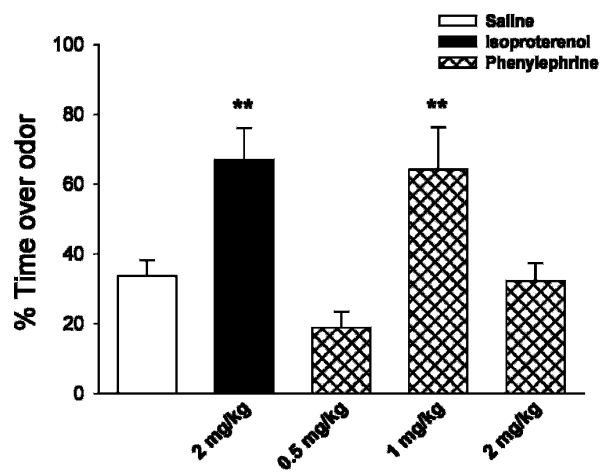

Figure 3. The $\alpha 1$-adrenoceptor agonist, phenylephrine, exhibits an inverted U-curve effect as an unconditioned stimulus in early preference learning. At a dose of $1 \mathrm{mg} / \mathrm{kg}$, phenylephrine is not significantly different from the learning control, isoproterenol $(2 \mathrm{mg} / \mathrm{kg})$, but is significantly different from the nonlearning saline control. Higher and lower doses of phenylephrine are ineffective for learning. ${ }^{* *} P<0.05$. $N$ values are five to six pups per group.

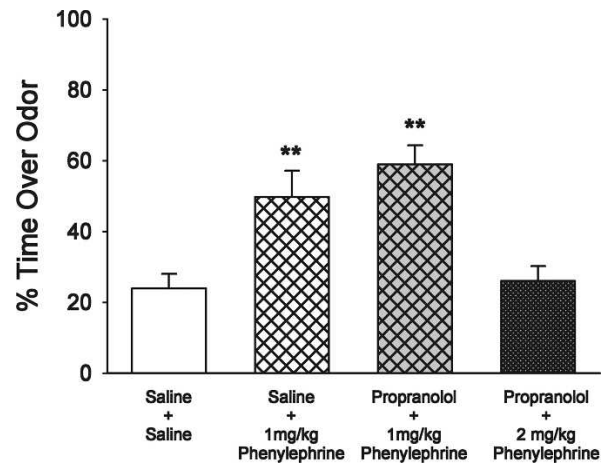

Figure 4. Even in the presence of the $\beta$-adrenoceptor antagonist, propranolol, the $\alpha 1$-adrenoceptor agonist, phenylephrine $(1 \mathrm{mg} / \mathrm{kg})$, is effective as the unconditioned stimulus in learning. Too much phenylephrine $(2 \mathrm{mg} / \mathrm{kg})$ in the presence of propranolol is ineffective as the unconditioned stimulus, which is similar to the finding shown in Figure 3. N values are 12 pups for each group. ${ }^{* *} P<0.01$ vs. nonlearning saline group.

learning targets are intrabulbar, this is not examined directly here. Each of the drugs used would also have effects at other sites and on other receptors, e.g., clonidine (Eglen et al. 1998), phenylephrine (Ishac et al. 1987; Gadek-Michalska et al. 1990; Watkins et al. 1990; Quigley et al. 2005), and salbutamol (Waldmeier 1981; Murugaiah and O'Donnell 1995; Garnier et al. 1997).

To estimate the intrabulbar drug concentrations of the systemic drugs that produced learning in the present study, we assumed pups were 70\% water (Mullins 1983) and lacked an effective blood-brain barrier for these drugs, in contrast to adults (Conway et al. 1987). Pups were previously shown to learn an odor preference with $50 \mu \mathrm{M}$ intrabulbar isoproterenol (Moriceau and Sullivan 2004). Our estimated systemic isoproterenol dose was $83 \mu \mathrm{M}$. In previous studies, halving or doubling this dose did not induce learning (Sullivan et al. 1989; Langdon et al. 1997). Dobutamine, the $\beta 1$-adrenoceptor agonist, was effective at 56 $\mu \mathrm{M}$. Phenylephrine was effective at $34 \mu \mathrm{M}$. Salbutamol was ineffective when tested up to an estimated concentration of $120 \mu \mathrm{M}$. While highly speculative, these estimates likely represent maximal levels that could occur in the olfactory bulb; thus, they are useful for addressing questions of selectivity. Since isoproterenol, dobutamine, and phenylephrine all exhibit inverted U-curves in their dose/response relationship to learning, their nonspecific effects, more likely to occur at higher doses, are less likely to account for the observed induction of learning seen here.

The effectiveness of dobutamine in the present study in inducing odor preference learning, supports our hypothesis of a critical interaction between the odor input to mitral cells and $\beta 1$-adrenoceptor activation of the same cells in the mediation of odor preference learning. This result is also consistent with evidence that $\beta$-adrenoceptor-mediated increases in cAMP and activation of the PKA phosphorylation cascade (Yuan et al. 2003a; McLean et al. 2005) participate causally in the acquisition of early odor preference learning.

Isoproterenol, the most commonly employed pharmacological agent as an unconditioned stimulus for odor preference learning, has a consistent inverted $U$ dose-response curve in terms of its role in learning. In the present study, for the $\beta$-adrenoceptor agonists, only dobutamine replicated the inverted Ucurve pattern, further supporting the hypothesis that $\beta 1$ adrenoceptors mediate the effect of isoproterenol as an unconditioned stimulus. The effective dose of dobutamine was half that of the $\beta 1 / \beta 2$-adrenoceptor agonist isoproterenol, which is also consistent with mediation by $\beta 1$-adrenoceptors since the tissue 


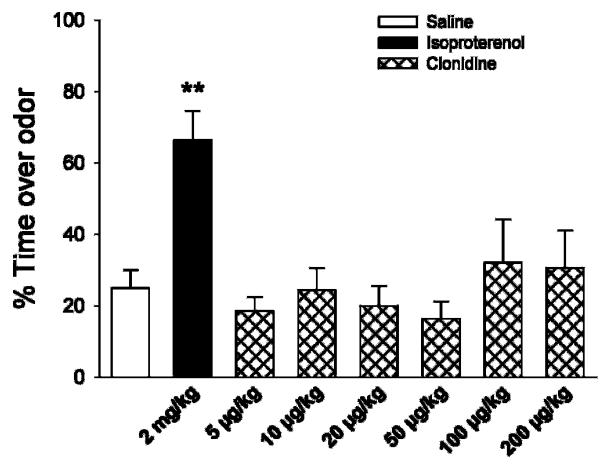

Figure 5. The $\alpha 2$-adrenoceptor agonist, clonidine, does not appear to act as an unconditioned stimulus because no dose used induced learning. The $\beta$-adrenoceptor agonist, isoproterenol, however, was effective as an unconditioned stimulus vs. the nonlearning saline group. ${ }^{* *} P<0.01$. N values ranged from six to 10 pups for each group.

concentrations of the two drugs are similar. Further studies might examine whether activation of $\beta 2$-adrenoceptors by salbutamol can shift the inverted U-curve of either isoproterenol or dobutamine leftward, testing a supportive role for $\beta 2$-adrenoceptors in early odor preference learning.

The density of $\alpha 1$-adrenoceptors in the olfactory bulb is among the highest in the mammalian brain (McCune et al. 1993; Pieribone et al. 1994). They have been implicated in enhancing the ability of peri-threshold odor nerve stimulation to excite mitral cells but have no effect on suprathreshold stimulation (Ciombor et al. 1999). However, terpinene, in the present study, is unlikely to have been peri-threshold for olfactory nerve activation.

The present study is the first report of $\alpha 1$-adrenoceptor activation acting as an unconditioned stimulus for odor preference learning in the rat pup. $\alpha 1$-Adrenoceptor activation also exhibited an inverted U-curve profile similar to that seen with the $\beta$-adrenoceptor agonists isoproterenol and dobutamine. In other studies, $\alpha 1$-adrenoceptor activation in the olfactory bulb increases feedback inhibition and GABA release (Mouly et al. 1995). Consistent with these effects, the late component of the olfactory nerve evoked potential is inhibited by locus coeruleus activation and antagonized by an $\alpha 1$-adrenoceptor blocker (Perez et al. 1987). This late component may represent feedback inhibition of granule cells onto mitral cells.

An $\alpha 1$-adrenoceptor-mediated increase in GABA release suggests a possible mechanism for odor preference learning consistent with our current model, which proposes that odor input interacts with increases in mitral cell cAMP to induce circuitry changes underlying odor preference. In the olfactory bulb, $\mathrm{GABA}_{\mathrm{B}}$ receptor activation can elevate cAMP in granule cells and in the external plexiform layer by a pathway independent of $\beta$-adrenoceptor activation (Olianas and Onali 1999). The external plexiform layer contains the dendrodendritic synaptic connections between granule and mitral cells. Mitral cells possess $\mathrm{GABA}_{\mathrm{B}}$ receptors (Panzanelli et al. 2004), and therefore, the cAMP elevation observed by Olianas and Onali (1999) in the external plexiform layer may have occurred in mitral cells, although it was implied that the elevation was within granule cell dendrites. Thus, the enhanced GABA feedback initiated by $\alpha 1$ adrenoceptors might, in this view, provide another route to increase cAMP in mitral cell dendrites (Fig. 6). $\alpha 1$-Adrenoceptor activation in the olfactory bulb also enhances $\beta$-adrenoceptormediated cAMP two to three times more effectively than in any other brain area (Stone and Herrera 1986) and may support the increases in cAMP induced by isoproterenol, just as $5-\mathrm{HT}_{2 \mathrm{~A} / \mathrm{C}}$ receptor activation has been postulated to do (Price et al. 1998;
Yuan et al. 2003b; McLean and Harley 2004). However, the effectiveness of $\alpha 1$-adrenoceptor activation, in the presence of propranolol, argues for an action separate from $\beta$-adrenoceptors in the present study. Phenylephrine itself has recently been reported to increase cAMP in two systems (Saeed et al. 2004; Gallego et al. 2005) and to couple to CREB phosphorylation through the PKA pathway in another system (Markou et al. 2004). We indicate this possibility in Figure 6. Investigating cAMP levels in the phenylephrine learning condition would test cAMP involvement in the phenylephrine-induced learning. The use of $G_{A B A}$ antagonists would assess whether any cAMP increase was directly or indirectly mediated. Alternatively, $\alpha 1$-adrenoceptor activation may act via a mechanism unrelated to cAMP. For example, $\alpha 1$ adrenoceptors most often act through second messenger systems via protein kinase C or MAP kinases (for a review, see Koshimizu et al. 2002). In this respect, $\alpha 1$-adrenoceptors could act directly on mitral cells (Hayar et al. 2001) and recruit intracellular signaling pathways unrelated to cAMP signaling to promote learning.

With stroking, $\beta$-adrenoceptor blockade is sufficient to prevent odor preference learning, suggesting that the $\alpha 1$-adrenoceptor stimulation produced by locus coeruleus norepinephrine release is not sufficient, on its own, to induce learning. If $\alpha 1$ adrenoceptor activation supports $\beta$-adrenoceptor-driven cAMP, however, it is likely that an $\alpha 1$-adrenoceptor antagonist might also prevent odor learning.

$\alpha 2$-Adrenoceptor activity has been shown previously in the olfactory bulb. Clonidine produces presynaptic disinhibition in the olfactory bulb by reducing glutamatergic drive to the granule cells and by reducing GABA feedback on the mitral cells (Trombley and Shepherd 1992; Trombley 1994). Mitral cell disinhibition by bicuculline produces odor preference learning in older pups when infused into the olfactory bulb at low doses (Okutani et al. 1999), but clonidine was ineffective at any dose tried in this study. Possibly the degree of disinhibition induced by clonidine in vivo is intermediate between the low level that produces preferences and the high level that produces aversions (Okutani et al. 1999), or disinhibition may be less effective in week-old pups. However, we have previously shown that a metabotropic glutamate agonist (DCG-IV) that also produces disinhibition of dendrodendritic feedback is an effective unconditioned stimulus for odor preference learning in younger pups (Rumsey et al. 2001). Further studies of clonidine, in conjunction with other disinhibi-

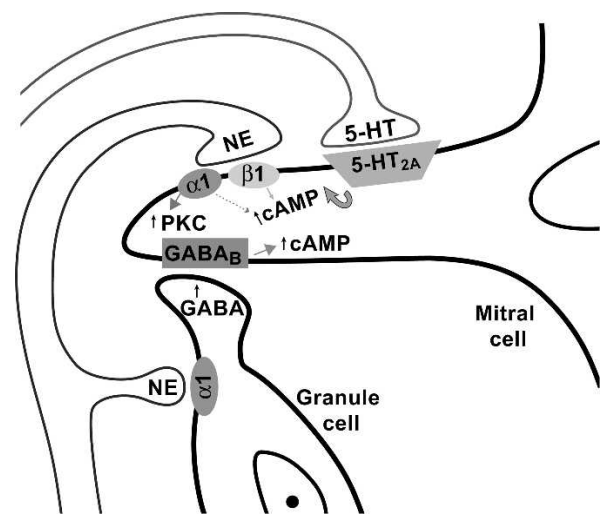

Figure 6. A simplified schematic showing the proposed direct and indirect influence of $\beta 1$ - and $\alpha 1$-adrenoceptors on mitral and granule cells in the olfactory bulb. The potential influence of the adrenoceptors as unconditioned stimuli on cAMP cascades in mitral cells is also illustrated. $\beta 1$-Adrenoceptors act directly on mitral cells to increase cAMP, while $\alpha 1$-adrenoceptors may act indirectly via granule cells and $\mathrm{GABA}_{\mathrm{B}}$ activation. $\alpha 1$-Adrenoceptors may also act directly on mitral cells to activate CAMP (see arrow), but the second messenger cascades are more likely through PKC or MAPK pathways. 
tors or with $\beta$-adrenoceptor activation, may reveal a helper role for these receptors.

In summary, this series of experiments is consistent with our hypothesis that $\beta 1$-adrenoceptor activation provides the unconditioned stimulus in odor preference learning. The inverted Ucurve pattern with the $\beta 1-$, but not the $\beta 2$-, adrenoceptor agonist strengthens the assumption that $\beta 1$-adrenoreceptor activation mediates the effects of isoproterenol as an unconditioned stimulus. These results also demonstrate that $\alpha 1-$, but not $\alpha 2-$, adrenoceptor activation may mediate a noradrenergic learning signal in the olfactory bulb.

\section{Acknowledgments}

This work was supported by CIHR MOP-53761 to J.H.M and C.W.H. We thank Richard Neuman for constructive comments on the manuscript.

\section{References}

Alberini, C.M. 1999. Genes to remember. J. Exp. Biol. 202: 2887-2891.

Arnsten, A.F. and Leslie, F.M. 1991. Behavioral and receptor binding analysis of the $\alpha 2$-adrenergic agonist, 5-bromo-6 [2-imidazoline-2-yl amino] quinoxaline (UK-14304): Evidence for cognitive enhancement at an $\alpha 2$-adrenoceptor subtype. Neuropharmacology 30: $1279-1289$.

Birnbaum, S.G., Podell, D.M., and Arnsten, A.F. 2000. Noradrenergic $\alpha-2$ receptor agonists reverse working memory deficits induced by the anxiogenic drug, FG7142, in rats. Pharmacol. Biochem. Behav. 67: 397-403.

Carlson, S., Tanila, H., Rama, P., Mecke, E., and Pertovaara, A. 1992. Effects of medetomidine, an $\alpha-2$ adrenoceptor agonist, and atipamezole, an $\alpha-2$ antagonist, on spatial memory performance in adult and aged rats. Behav. Neural Biol. 58: 113-119.

Ciombor, K.J., Ennis, M., and Shipley, M.T. 1999. Norepinephrine increases rat mitral cell excitatory responses to weak olfactory nerve input via $\alpha-1$ receptors in vitro. Neuroscience 90: 595-606.

Conway, P.G., Tejani-Butt, S., and Brunswick, D.J. 1987. Interaction of $\beta$ adrenergic agonists and antagonists with brain $\beta$ adrenergic receptors in vivo. J. Pharmacol. Exp. Ther. 241: 755-762.

Coull, J.T., Sahakian, B.J., and Hodges, J.R. 1996. The $\alpha(2)$ antagonist idazoxan remediates certain attentional and executive dysfunction in patients with dementia of frontal type. Psychopharmacology (Berl.) 123: $239-249$

Eglen, R.M., Hudson, A.L., Kendall, D.A., Nutt, D.J., Morgan, N.G., Wilson, V.G., and Dillon, M.P. 1998. "Seeing through a glass darkly": Casting light on imidazoline "I" sites. Trends Pharmacol. Sci. 19: 381-390.

Gadek-Michalska, A., Turon, M., Bugajski, J., and Polczynska-Konior, G. 1990. Effects of systemic and intracerebroventricular phenylephrine and clonidine on corticosterone secretion in rats. Endocrinol. Exp. 24: $249-258$

Gallego, M., Setien, R., Puebla, L., Boyano-Adanez, M.C., Arilla, E., and Casis, O. 2005. $\alpha 1$-Adrenoceptors stimulate a $\mathrm{G} \alpha$ s protein and reduce the transient outward $\mathrm{K}+$ current via a cAMP/PKA-mediated pathway in the rat heart. Am. J. Physiol Cell. Physiol. 288: C577-C585.

Garnier, V., Zini, R., Sapena, R., and Tillement, J.P. 1997. A match between binding to $\beta$-adrenoceptors and stimulation of adenylyl cyclase parameters of (-)isoproterenol and salbutamol on rat brain. Pharmacol. Res. 35: 303-312.

Gibbs, M.E. and Summers, R.J. 2003. $\alpha 2$-Adrenoceptors in the basal ganglia have a role in memory consolidation and reinforcement. Neuropharmacology 45: 355-367.

Hayar, A., Heyward, P.M., Heinbockel, T., Shipley, M.T., and Ennis, M. 2001. Direct excitation of mitral cells via activation of $\alpha 1$-noradrenergic receptors in rat olfactory bulb slices. $J$. Neurophysiol. 86: 2173-2182.

Ishac, E.J., Eskay, R., Hirata, F., Axelrod, J., and Kunos, G. 1987. Adrenergic regulation of $\beta$-endorphin secretion from anterior pituitary in conscious rats: Effects of thyroid state. Endocrinology 120: $1073-1078$.

Koshimizu, T.A., Yamauchi, J., Hirasawa, A., Tanoue, A., and Tsujimoto, G. 2002. Recent progress in $\alpha 1$-adrenoceptor pharmacology. Biol. Pharm. Bull. 25: 401-408.

Langdon, P.E., Harley, C.W., and McLean, J.H. 1997. Increased $\beta$ adrenoceptor activation overcomes conditioned olfactory learning deficits induced by serotonin depletion. Dev. Brain Res. 102: 291-293.

Markou, T., Hadzopoulou-Cladaras, M., and Lazou, A. 2004.
Phenylephrine induces activation of CREB in adult rat cardiac myocytes through MSK1 and PKA signaling pathways. J. Mol. Cell Cardiol. 37: 1001-1011.

McCune, S.K., Voigt, M.M., and Hill, J.M. 1993. Expression of multiple $\alpha$ adrenergic receptor subtype messenger RNAs in the adult rat brain. Neuroscience 57: 143-151.

McLean, J.H. and Harley, C.W. 2004. Olfactory learning in the rat pup: A model that may permit visualization of a mammalian memory trace. NeuroReport 15: 1691-1697.

McLean, J.H., Darby-King, A., Sullivan, R.M., and King, S.R. 1993. Serotonergic influence on olfactory learning in the neonate rat. Behav. Neural Biol. 60: 152-162.

McLean, J.H., Darby-King, A., and Hodge, E. 1996. 5-HT 2 receptor involvement in conditioned olfactory learning in the neonate rat pup. Behav. Neurosci. 110: 1426-1434.

McLean, J.H., Harley, C.W., Darby-King, A., and Yuan, Q. 1999. pCREB in the neonate rat olfactory bulb is selectively and transiently increased by odor preference-conditioned training. Learn. Mem. 6: 608-618.

McLean, J.H., Cui, W., Darby-King, A., and Harley, C.W. 2004. Cyclic AMP actions in neonate rat odor preference learning: Causality, oscillations and memory extension. Soc. Neurosci. Abst. 34: 897.21.

McLean, J.H., Darby-King, A., and Harley, C.W. 2005. Potentiation and prolongation of long-term odor memory in neonate rats using a phosphodiesterase inhibitor. Neuroscience 135: 329-334.

Moriceau, S. and Sullivan, R.M. 2004. Unique neural circuitry for neonatal olfactory learning. J. Neurosci. 24: 1182-1189.

Mouly, A.M., Elaagouby, A., and Ravel, N. 1995. A study of the effects of noradrenaline in the rat olfactory bulb using evoked field potential response. Brain Res. 681: 47-57.

Mullins, M.M. 1983. Body fluid volumes in prehypertensive spontaneously hypertensive rats. Am. J. Physiol 244: H652-H655.

Murugaiah, K.D. and O'Donnell, J.M. 1995. Facilitation of norepinephrine release from cerebral cortex is mediated by B2-adrenergic receptors. Life Sci. 57: L327-L332.

Nakamura, S., Kimura, F., and Sakaguchi, T. 1987. Postnatal development of electrical activity in the locus ceruleus. $J$. Neurophysiol. 58: 510-524.

Nicholas, A.P., Pieribone, V.A., and Hokfelt, T. 1993. Cellular localization of messenger RNA for $\beta-1$ and $\beta-2$ adrenergic receptors in rat brain: An in situ hybridization study. Neuroscience 56: $1023-1039$

Okutani, F., Yagi, F., and Kaba, H. 1999. GABAergic control of olfactory learning in young rats. Neuroscience 93: 1297-1300.

Olianas, M.C. and Onali, P. 1999. GABA(B) receptor-mediated stimulation of adenylyl cyclase activity in membranes of rat olfactory bulb. Br. J. Pharmacol. 126: 657-664.

Panzanelli, P., Lopez-Bendito, G., Lujan, R., and Sassoe-Pognetto, M. 2004. Localization and developmental expression of GABA(B) receptors in the rat olfactory bulb. J. Neurocytol. 33: 87-99.

Perez, H., Hernandez, A., and Almli, C.R. 1987. Locus coeruleus stimulation modulates olfactory bulb evoked potentials. Brain Res. Bull. 18: 767-770.

Pieribone, V.A., Nicholas, A.P., Dagerlind, A., and Hokfelt, T. 1994 Distribution of $\alpha 1$ adrenoceptors in rat brain revealed by in situ hybridization experiments utilizing subtype-specific probes. $J$. Neurosci. 14: 4252-4268.

Pittenger, C. and Kandel, E.R. 2003. In search of general mechanisms for long-lasting plasticity: Aplysia and the hippocampus. Philos. Trans. $R$. Soc. Lond. B. Biol. Sci. 358: 757-763.

Price, T.L., Darby-King, A., Harley, C.W., and McLean, J.H. 1998. Serotonin plays a permissive role in conditioned olfactory learning induced by norepinephrine in the neonate rat. Behav. Neurosci. 112: 1430-1437.

Quigley, K.S., Myers, M.M., and Shair, H.N. 2005. Development of the baroreflex in the young rat. Auton. Neurosci. 121: 26-32.

Rangel, S. and Leon, M. 1995. Early odor preference training increases olfactory bulb norepinephrine. Dev. Brain Res. 85: 187-191.

Rumsey, J.D., Darby-King, A., Harley, C.W., and McLean, J.H. 2001. Infusion of the metabotropic receptor agonist, DCG-IV, into the main olfactory bulb induces olfactory preference learning in rat pups. Dev. Brain Res. 128: 177-179.

Saeed, A.E., Parmentier, J.H., and Malik, K.U. 2004. Activation of $\alpha 1 \mathrm{~A}$-adrenergic receptor promotes differentiation of rat-1 fibroblasts to a smooth muscle-like phenotype. BMC Cell Biol. 5: 47.

Sara, S.J. and Devauges, V. 1989. Idazoxan, an $\alpha-2$ antagonist, facilitates memory retrieval in the rat. Behav. Neural Biol. 51: 401-411.

Spreng, M., Cotecchia, S., and Schenk, F. 2001. A behavioral study of $\alpha-1 b$ adrenergic receptor knockout mice: Increased reaction to novelty and selectively reduced learning capacities. Neurobiol. Learn. Mem. 75: 214-229.

Stone, E.A. and Herrera, A.S. 1986. $\alpha$-Adrenergic modulation of cyclic

\section{Learning \& Memory}


AMP formation in rat CNS: Highest level in olfactory bulb. Brain Res. 384: 401-403.

Sullivan, R.M. and Leon, M. 1987. One-trial olfactory learning enhances olfactory bulb responses to an appetitive conditioned odor in 7-day-old rats. Dev. Brain Res. 35: 307-311.

Sullivan, R.M. and Wilson, D.A. 1991. The role of norepinephrine in the expression of learned olfactory neurobehavioral responses in infant rats. Psychobiology 19: 308-312.

. 1994. The locus coeruleus, norepinephrine, and memory in newborns. Brain Res. Bull. 35: 467-472.

Sullivan, R.M., Wilson, D.A., and Leon, M. 1989. Norepinephrine and learning-induced plasticity in infant rat olfactory system. J. Neurosci. 9: 3998-4006.

Sullivan, R.M., McGaugh, J.L., and Leon, M. 1991a. Norepinephrineinduced plasticity and one-trial olfactory learning in neonatal rats. Dev. Brain Res. 60: 219-228.

Sullivan, R.M., Taborsky Barba, S., Mendoza, R., Itano, A., Leon, M., Cotman, C.W., Payne, T.F., and Lott, I. 1991b. Olfactory classical conditioning in neonates. Pediatrics 87: 511-518.

Sullivan, R.M., Zyzak, D.R., Skierkowski, P., and Wilson, D.A. 1992. The role of olfactory bulb norepinephrine in early olfactory learning. Dev. Brain Res. 70: 279-282.

Sullivan, R.M., Stackenwalt, G., Nasr, F., Lemon, C., and Wilson, D.A. 2000. Association of an odor with activation of olfactory bulb noradrenergic $\beta$-receptors or locus coeruleus stimulation is sufficient to produce learned approach responses to that odor in neonatal rats. Behav. Neurosci. 114: 957-962.

Trombley, P.Q. 1994. Noradrenergic modulation of synaptic transmission between olfactory bulb neurons in culture: Implications to olfactory learning. Brain Res. Bull. 35: 473-484.

Trombley, P.Q. and Shepherd, G.M. 1992. Noradrenergic inhibition of synaptic transmission between mitral and granule cells in mammalian olfactory bulb cultures. J. Neurosci. 12: 3985-3991.

Waldmeier, P.C. 1981. Stimulation of central serotonin turnover by B-adrenoceptor agonists. Naunyn Schmiedebergs Arch. Pharmacol. 317: 115-119.

Watkins, L.R., Thurston, C.L., and Fleshner, M. 1990. Phenylephrineinduced antinociception: Investigations of potential neural and endocrine bases. Brain Res. 528: 273-284.

Woo, C.C. and Leon, M. 1995. Distribution and development of $\beta$-adrenergic receptors in the rat olfactory bulb. J. Comp. Neurol. 352: $1-10$.

Yin, J.C. and Tully, T. 1996. CREB and the formation of long-term memory. Curr. Opin. Neurobiol. 6: 264-268.

Yuan, Q., Harley, C.W., Darby-King, A., Neve, R.L., and McLean, J.H. 2003a. Early odor preference learning in the rat: Bidirectional effects of cAMP response element-binding protein (CREB) and mutant CREB support a causal role for phosphorylated CREB. J. Neurosci. 23: 4760-4765.

Yuan, Q., Harley, C.W., and McLean, J.H. 2003b. Mitral cell $\beta 1$ and $5-\mathrm{HT}_{2 \mathrm{~A}}$ receptor colocalization and cAMP coregulation: A new model of norepinephrine-induced learning in the olfactory bulb. Learn. Mem. 10: 5-15.

Received August 22, 2005; accepted in revised form November 3, 2005. 


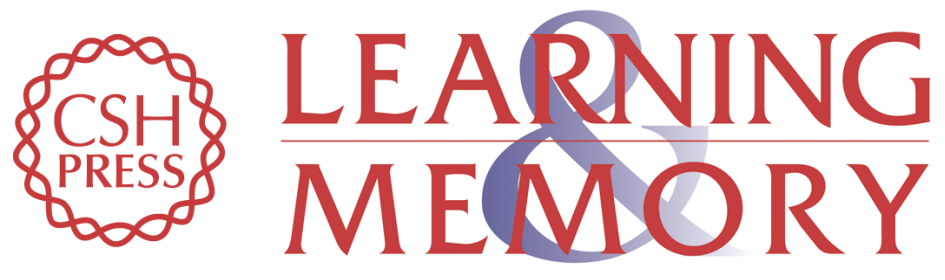

\section{$\beta 1$-Adrenoceptor or $\alpha 1$-adrenoceptor activation initiates early odor preference learning in rat pups: Support for the mitral cell/cAMP model of odor preference learning}

Carolyn W. Harley, Andrea Darby-King, Jennifer McCann, et al.

Learn. Mem. 2006, 13:

Access the most recent version at doi:10.1101/lm.62006

References This article cites 59 articles, 9 of which can be accessed free at:

http://learnmem.cshlp.org/content/13/1/8.full.html\#ref-list-1

License

Email Alerting

Receive free email alerts when new articles cite this article - sign up in the box at the Service top right corner of the article or click here. 